\title{
Effect of platelet-rich and platelet-poor plasma on peri-implant innervation in dog mandibles
}

\author{
Dandan Song ${ }^{1 *}$ (D), Yan Huang ${ }^{1,2}$, Jeroen Van Dessel ${ }^{1}$, Sohaib Shujaat ${ }^{1}$, Kaan Orhan $^{1,3}$, Tim Vangansewinkel ${ }^{4}$,
} Kathleen Van den Eynde ${ }^{5}$, Ivo Lambrichts ${ }^{4}$, Tania Roskams ${ }^{5}$, Constantinus Politis ${ }^{1}$ and Reinhilde Jacobs ${ }^{1,6}$

\begin{abstract}
Background: Autologous plasma fractions, such as platelet-rich plasma (PRP) and platelet-poor plasma (PPP), contain growth factors that can enhance neural cell survival and are therefore likely to have the ability to promote nerve regeneration. The present study compared the effect of PRP and PPP application on myelinated nerve density and diameter in the peri-implant bone region. In addition, the effect of healing time on nerve regeneration was assessed.

Materials and methods: Nine beagle dogs randomly received 54 dental implants in the bilateral mandible according to a split-mouth design. Each implant was randomly assigned to one of three implant protocols: delayed implant placement with delayed loading (DIP + DL) with local application of PRP, DIP + DL with local application of PPP and DIP + DL without any plasma additive. The animals were euthanized at 1, 3, and 6 months after loading (3 dogs per time point). Block biopsies were prepared for histomorphometry in the peri-implant bone within $500 \mu \mathrm{m}$ around the implants.

Results: Myelinated nerve fibers were identified in the trabecular bone and in the osteons near the implants surface. The nerve fibers in the PRP group (median \pm IQR; $2.88 \pm 1.55 \mu \mathrm{m}$ ) had a significantly $(p<0.05)$ greater diameter compared to the PPP $(2.40 \pm 0.91 \mu \mathrm{m})$ and control $(2.11 \pm 1.16 \mu \mathrm{m})$ group. The nerve diameter after 6 months healing $(3.18 \pm 1.58 \mu \mathrm{m})$ was significantly $(p<0.05)$ greater compared to $1(2.08 \pm 0.89 \mu \mathrm{m})$ and $3(2.49 \pm 1.22 \mu \mathrm{m})$ months. No significant difference was found for myelinated nerve density between groups and healing time.

Conclusions: The present study showed that the healing time significantly influenced the diameter of the myelinated nerve fibers in peri-implant bone. PRP exerted a significant effect on the diameter of the myelinated nerve fibers as compared to PPP. Large-scale animal studies and longer follow-up periods are needed to confirm these findings and to verify whether platelet plasma can facilitate nerve regeneration process.
\end{abstract}

Keywords: Platelet-rich plasma, Platelet-poor plasma, Dental implant, Histomorphometry, Myelinated nerve fibers, Innervation

\section{Background}

Dental implant surgery is one of the most widely accepted procedures for replacing missing dentition without harming the neighboring healthy teeth. The survival of the dental implant is dependent on successful osseointegration, defined as the direct structural and

\footnotetext{
* Correspondence: dandansong9015@gmail.com

'OMFS IMPATH Research Group, Department of Imaging and Pathology,

Faculty of Medicine, KU Leuven and Oral and Maxillofacial Surgery, University Hospitals Leuven, Campus Sint-Rafaël, Kapucijnenvoer 33, BE-3000 Leuven, Belgium

Full list of author information is available at the end of the article
}

functional connection between vital bone and dental implant surface under a functional load. If optimal osseointegration is not achieved, biological failure and consequent implant loss can occur [1]. The residual alveolar ridge constantly undergoes modeling and remodeling following tooth extraction [2].

Maxillary and mandibular alveolar bone contains multiple nerve fibers, which are responsible for detecting mechanical loading-induced signals through the mechanosensitive cells knows as mechanoreceptors $[3,4]$. These receptors are responsible for transmitting information 
from nerve endings on the magnitude, direction, and rate of occlusal load for sensory perception and neuromotor control. The mechanism of such receptors involves the transmission of sensitivity and pain when natural teeth are in hyperocclusion. Degeneration of the alveolar structure or periodontal ligaments (PDLs) can lead to the impairment of these receptors, hence effecting the neurosensory pathway [5]. As osseointegrated dental implants are highly susceptible to occlusal overload, the damaged receptors can directly result in the loss of fine exteroception [6]. The existing mechanoreceptors in the bone and periosteum play a significant role in tactile function following implant loading. The threshold level of active tactile force in implant-supported prostheses has been suggested to be lower than the complete denture but similar to that of the natural tooth [7-10].

Previous studies reported a partial restoration of peripheral sensory feedback pathway following implant placement. However, the underlying mechanism of this phenomenon remains unknown [11, 12]. Furthermore, neurophysiological and psychophysical evidence confirms peripheral receptor activation after active or passive loading of the implant. It is assumed that the latter could cause activation of endosseous and/or periosteal receptors in the peri-implant tissue [13]. In addition, histomorphological studies showed the presence of functional mechanoreceptors in the peri-implant region which might have been originally located in the periodontal ligament and neighboring periosteum [14, 15].

Myelinated nerve fibers are the most effective sensory signal transporters responsible for carrying these mechanoreceptors [16]. Several treatment strategies have been utilized for the regeneration of mechanoreceptors around osseointegrated dental implant which include, reconstruction of the peri-implant ligament [17], transplantation of Schwann cells (SCs) [18], injection of neuropeptides (e.g., calcitonin gene-related peptide- $\alpha$ ) [19], and application of various implant placement and loading protocols [20]. Nevertheless, the clinical application of these therapies in implant surgery remains ambiguous.

Autologous plasma fractions, such as platelet-rich plasma (PRP) and platelet-poor plasma (PPP) have been utilized in dental implantology for stimulating new bone formation [21], angiogenesis [22], and peripheral nerve regeneration [23]. PRP is obtained by differential centrifugation of peripheral blood which divides the plasma, platelets, and leukocytes from red blood cells to form an upper plasma layer and intermediate buffy coat. The upper layer and superficial buffy coat are centrifuged for a second time to form the final PRP product, whereas, PPP is the residual plasma once the PRP is extracted [24]. The clinical potential of platelet concentrates depends on the number of platelets and the concentration of growth factors. Various growth factors, such as transforming growth factor- $\beta$ (TGF- $\beta$ ), platelet-derived growth factor (PDGF), transforming growth factor (TGF), platelet factor interleukin (IL), vascular endothelial growth factor (VEGF), insulin-like growth factor (IGF), and basic fibroblast growth factor (bFGF), contained in the alpha-granules of platelets have been known be responsible for PRP-related effects. Although recent studies showed that PRP and PPP have comparable effects on bone [21] and blood vessel formation [22], no evidence is available comparing the effect of these two fractions on nerve innervation in the periimplant bone. Therefore, the purpose of this study was to assess the effect of PRP and PPP on myelinated nerve density and diameter following delayed implant placement and delayed loading. In addition, the effect of healing time on peri-bone innervation was evaluated following 1, 3, and 6 months after loading.

\section{Materials and methods Study design}

The study was approved by the Bioethics Committee of Sichuan University (reference number: WCCSIRB-D2014-010). A split-mouth randomized study was designed in nine healthy male beagle dogs. The housing and feeding condition for all experimental dogs strictly followed the general program at Experimental Animal Center of Laboratory of Biotherapy.

\section{Sample size calculation}

The minimum required sample size was calculated using the discrepancy in myelinated nerve diameter for delayed implant placement with delayed loading (1.07 \pm $0.18 \mu \mathrm{m})$ and natural socket healing $(1.23 \pm 0.19 \mu \mathrm{m})$ obtained from a study with similar design [25]. An a priori power analysis in G*power 3.1 recommended minimum sample size of 18 peri-implant bone samples when assuming $80 \%$ power and $\alpha$ of 0.05 [26].

\section{Surgical procedure}

All animals (average weight $15.3 \mathrm{~kg}$ ) received 1 week of prophylactic antibiotic therapy prior to and after surgery (Gentamycin Sulphate $300 \mathrm{mh}$, Tianjin Pharmaceutical, Tianjin, China). Bilateral extraction of mandibular third premolar, fourth premolar, and first molar was carried out. All surgeries were performed by the same oral and maxillofacial surgeon. After 1 month of natural healing, six dental implants without surface spiral burr (Beijing Leiden Biomaterial implant system, diameter $3.3 \mathrm{~mm} /$ length $8 \mathrm{~mm}$ ) obtained from Leiden Biomaterial Limited Company, (Beijing, China) were placed bilaterally in the mandible of each dog. The surgical procedures were performed under general anesthesia with Sumianxin $(0.1$ $\mathrm{ml} / \mathrm{kg}$ xylazine hydrochloride, Changchun Military Academy of Medical Sciences, Changchun, China) and 
local anesthesia (2-4 ml lidocaine $2 \%$ epinephrine, Tianjin Pharmaceutical Co. Ltd, Tianjin, China) was used at the surgical sites. The implant body part which was buried into alveolar bone was coated with a thin layer of plasma-sprayed hydroxyapatite (HA). Each implant was randomly assigned to one of the three implant protocols: delayed implant placement with delayed loading (DIP + DL) with a local application of PRP, DIP + DL with local application of PPP and DIP + DL without any plasma additive (Fig. 1). The surgeon was blinded to the allocation process during tooth extraction but aware of the exact position of implant placements. A crown was fabricated and attached to each implant at one month following surgery.

\section{Preparation and application of PPP and PRP}

A double-centrifugation protocol was followed as suggested by Lee et al. [27]. Five milliliters of fresh whole blood was withdrawn from the foreleg vein of each dog and transferred into a sterile syringe, containing $1 \mathrm{ml}$ of sodium citrate anticoagulant solution. The whole blood was first centrifuged (Allegra X 30R centrifuge, CA, USA) at $700 \mathrm{~g}$ for $8 \mathrm{~min}$ and then separated into four layers. Thereafter, supernatant plasma with a buffy coat was separated and transferred to a new centrifugation tube. It underwent a second centrifugation at $1600 \mathrm{~g}$ for $8 \mathrm{~min}$. Finally, $1 \mathrm{ml}$ of PPP and PRP were obtained separately and each implant in test groups was dipped in PPP and PRP solution prior to insertion in the alveolus.

\section{Occlusion restoration}

The surgical condition and occlusion restoration were kept similar for all groups. All tissue-level implants were placed with their shoulders parallel to the level of marginal bone. Customized posts with resin crown (flowable resin composite under halogen light-curing unit for 20 s) were prepared with a resin cement (RelyX, Unicem, RX, 3M ESPE, St. Paul, USA). Occlusal contacts were kept edge-to-edge between implants and opposing natural teeth. The contacts were checked with an articulating paper $(20 \mu \mathrm{m}$ thick, Accufilm II, RX, 3M ESPE, St. Paul, USA).

\section{Animal sacrifice and histology}

All dogs were healthy with clinically stable implants and normal surrounding soft tissue before sacrifice. Three dogs were randomly chosen utilizing a direct sampling technique at 1,3 , and 6 months' time points (T1, T3, and T6). They were sacrificed using an overdose of xylazine hydrochloride (intravenous injection)

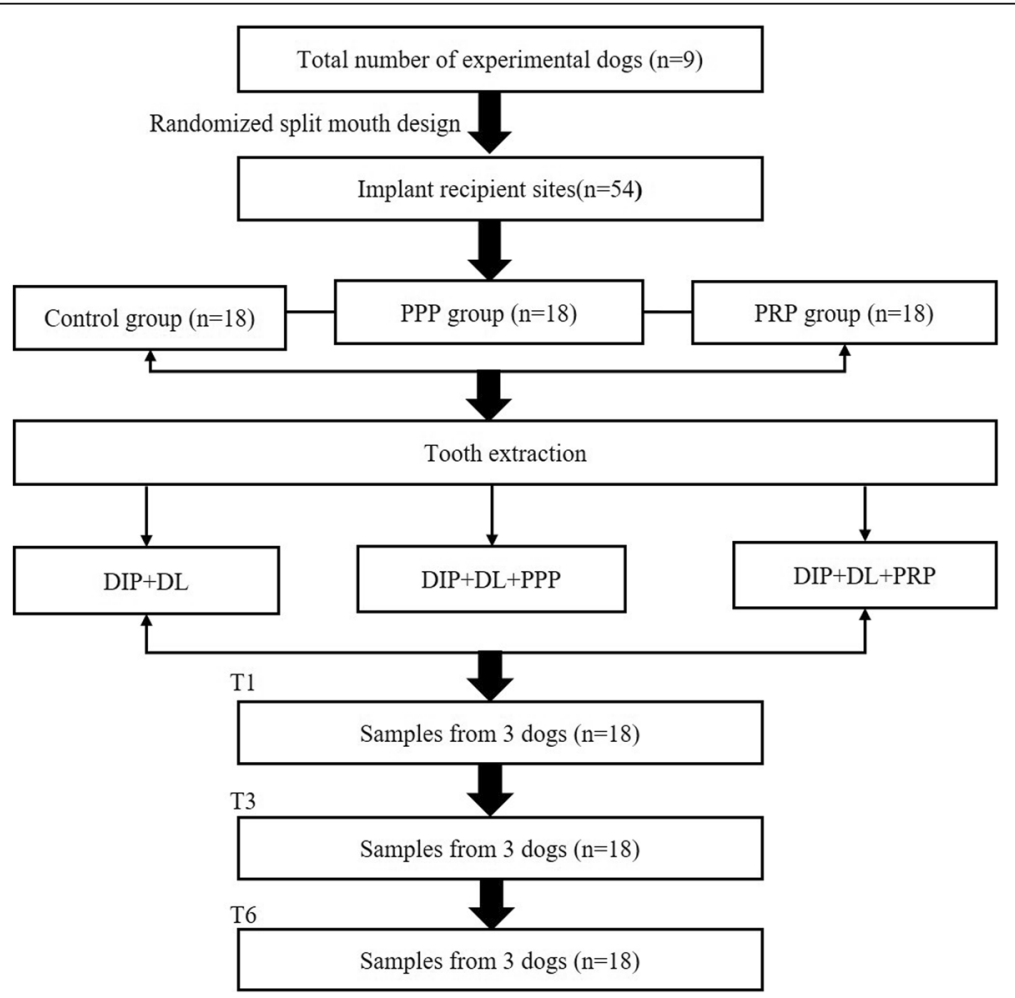

Fig. 1 Flow chart of study design. DIP+DL, delayed implant placement and delayed loading. PPP, platelet-poor plasma; PRP, platelet-rich plasma; T1, 1 month healing time; T3, 3 months healing time; T6 6 months healing time 
and immediate perfusion of $4 \%$ paraformaldehyde and $0.0125 \%$ glutaraldehyde in $0.1 \mathrm{M}$ phosphate buffer (pH 7.4). Specimen blocks were immersed in $0.5 \mathrm{~mol} /$ $\mathrm{L}$ ethylenediaminetetraacetic acid (EDTA) phosphatebuffered saline ( $\mathrm{pH} 7.4)$ at $4{ }^{\circ} \mathrm{C}$ for 10 months, enabling easy removal of the implants using surgical forceps without damaging the samples. After dehydrated and fully infiltrated by paraffin, thin serial sections $(\sim 6 \mu \mathrm{m})$ were obtained by cutting in a buccallingual direction. All collected sections were then stained with Masson trichrome stain for histological analysis and detection of myelinated nerve fibers.

\section{Immunohistochemistry}

The presence of myelinated nerve structures was confirmed with immunohistochemistry (IHC) by applying a labeled avidin-biotin method [28]. Sections were deparaffinized and microwaved using a $10-\mathrm{mm}$ citrate buffer (pH 6.0). Thereafter, $0.5 \% \mathrm{H}_{2} \mathrm{O}_{2}$ was applied to suppress endogenous peroxidase activity for reducing background staining. The unoccupied binding sites were blocked with $10 \%$ normal goat serum. Staining of the sections was carried out with primary antibody mouse monoclonal anti-neuropeptide Y (NPY, Santa Cruz Biotechnology, CA, USA, 1:50) followed by pretreatment with citrate ( $\mathrm{pH}$ 6.0).

\section{Histomorphometric analysis}

Digitization and evaluation of three serial sections from every sample was performed with MiraxScan (Carl Zeiss, Göttingen, Germany). A single observer (DS), who was blinded to implant groups, evaluated the density (number of myelinated nerves $/ \mathrm{mm}^{2}$ ) and outer diameter of myelinated fibers $(\mu \mathrm{m})$ on $\mathrm{a} \times 100$ magnified image using Fiji software (LOCI in Madison, WI, USA). A region of interest (ROI) with a distance of $500 \mu \mathrm{m}$ away from the implant surface was selected (Fig. 2), which is most likely to be influenced by the pressure from dental implant [29]. The partial fibers at borders of selected ROIs, myelinated nerve bundles and isolated axons in inferior alveolar nerve canal were excluded from evaluation.

\section{Statistical analysis}

Normality in the distribution of data was assessed graphically and with the Shapiro-Wilk test. Non-parametric statistical tests were chosen by means of small sample size and non-linear data distribution. The descriptive analysis expressed data as median and interquartile range. The Kruskal-Wallis test was used to compare nerve density and shortest diameter values between implant protocols (control, PPP and PRP group) and time points (T1, T3, and T6). Dunn-Bonferroni corrected post hoc tests were used to explore significant interaction effects. A significance level $\alpha$ of $5 \%$ was

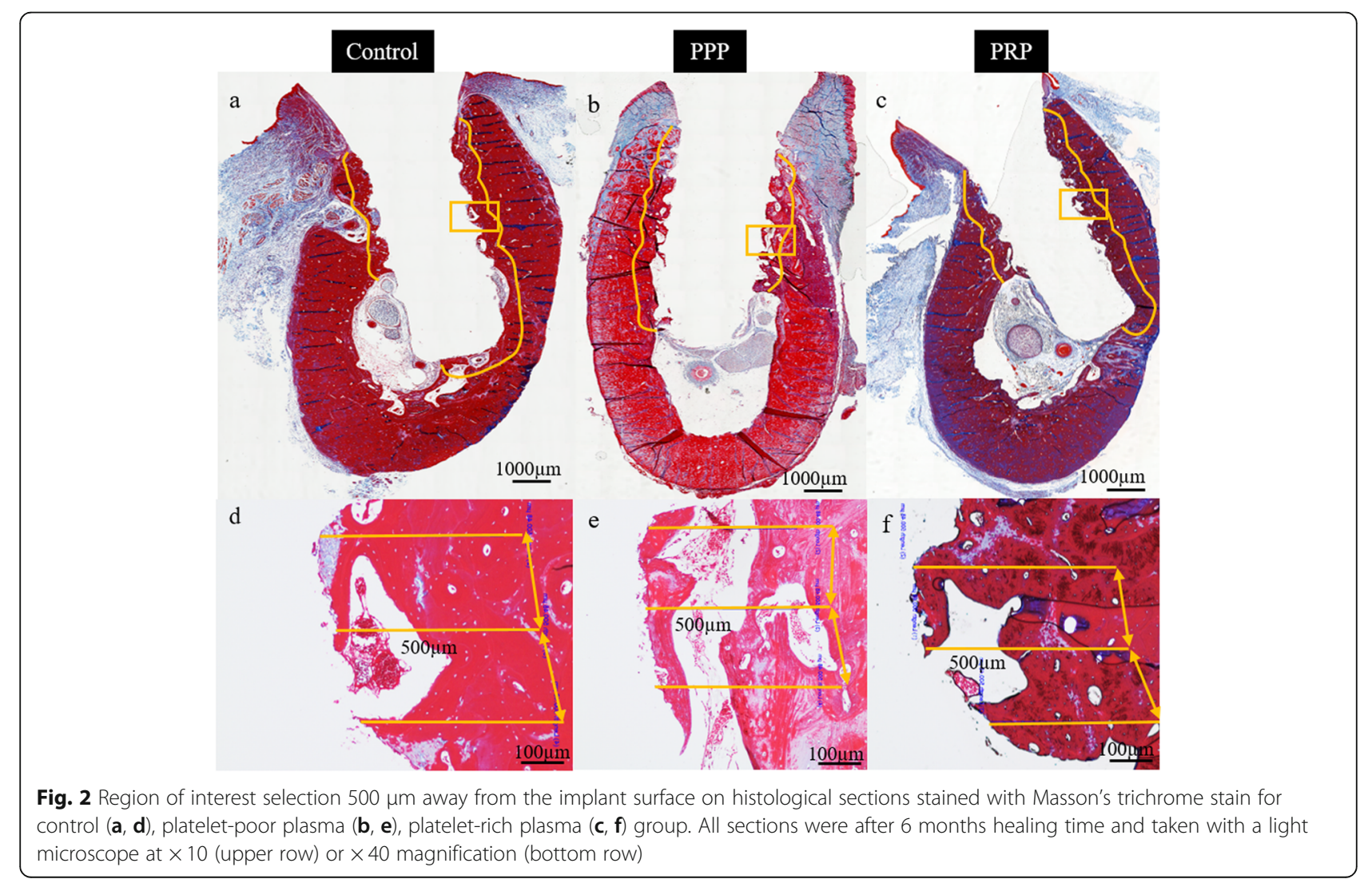


considered for all tests. Statistical analysis was performed in SPSS (IBM, NY, USA).

\section{Results}

All animals recovered well after implant placement and loading procedures without any clinical signs of infection or inflammation. All implants were clinically stable until euthanasia. Histological observation showed myelinated nerve fibers in the osteons near the implant surface and trabecular bone around the implant (Fig. 2). Nerve fibers were primarily dispersed perivascular and oriented according to the axis of the blood vessels. No difference was observed in the myelinated nerve density between the three groups $(p=$ $0.58)$ and time points $(p=0.29)$ (Figs. 3 and 5). However, there was a significant $(p<0.001)$ difference between the three implant groups related to nerve diameter (Figs. 3 and 5). The nerve fiber diameter in the PRP group was greater than in the PPP $(p=$ $0.02)$ and control $(p<0.001)$ group (Fig. 5). Overall, healing time significantly $(p<0.001)$ influenced myelinated nerve fiber diameter (Figs. 4 and 5). An increase in nerve diameter was observed at 6 months healing time compared to $1(p<0.001)$ and $3(p=$ 0.002) months (Fig. 5).

\section{Discussion}

The periodontal mechanoreceptors are an important component of the stomatognathic system. Tooth extraction leads to impairment of osseoperception by damaging these receptors [30]. The application of PRP has been demonstrated and proven to be beneficial for repairing damaged nerve fibers and receptors [31, 32]. Evidence suggests successful application of PRP for inducing nerve regeneration when the traumatic gaps of nerve structures are less than $3 \mathrm{~cm}$ long [33]. While the fact that the defects around dental implants are normally not as large as peripheral nerve defects might make the regeneration of peri-implant nerve fibers more feasible. Based on this fact, the present study was conducted to quantify the density and diameter of myelinated nerve fibers in peri-implant bone following local application of PRP and PPP. Moreover, the study focused on the clinical hypothesis that PRP contains numerous growth factors for promoting nerve growth.

The amount of growth factors in platelet plasma vary widely amongst different species. Van den Dolder et al. demonstrated in a comparative study that humans had a higher concentration of growth factors compared to other animal models [34]. Considering these differences amongst species, we applied regular double centrifugated protocol and separately transferred both the low

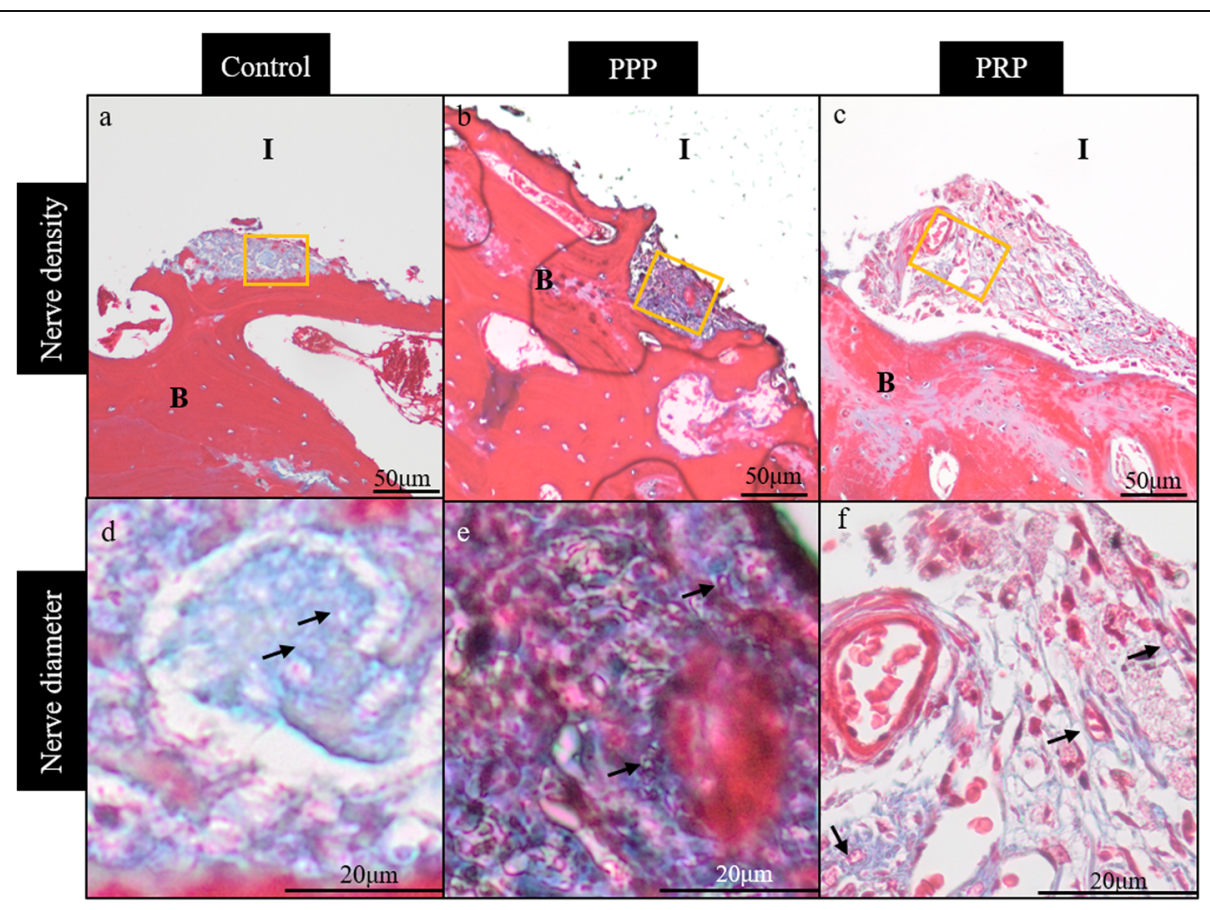

Fig. 3 Histological sections stained with Massons's trichrome stain for control (a, d), platelet-poor plasma (b, e), platelet-rich plasma (c, f) group near the implant surface. No difference was observed in the myelinated nerve density between the three groups (upper row). The nerve fiber diameter in the PRP group was greater than in the control and PPP group (see arrows, bottom row). All sections derive from 6 months healing time and taken with a light microscope at $\times 20$ (upper row) or $\times 40$ magnification (bottom row). I, implant; B, bone 


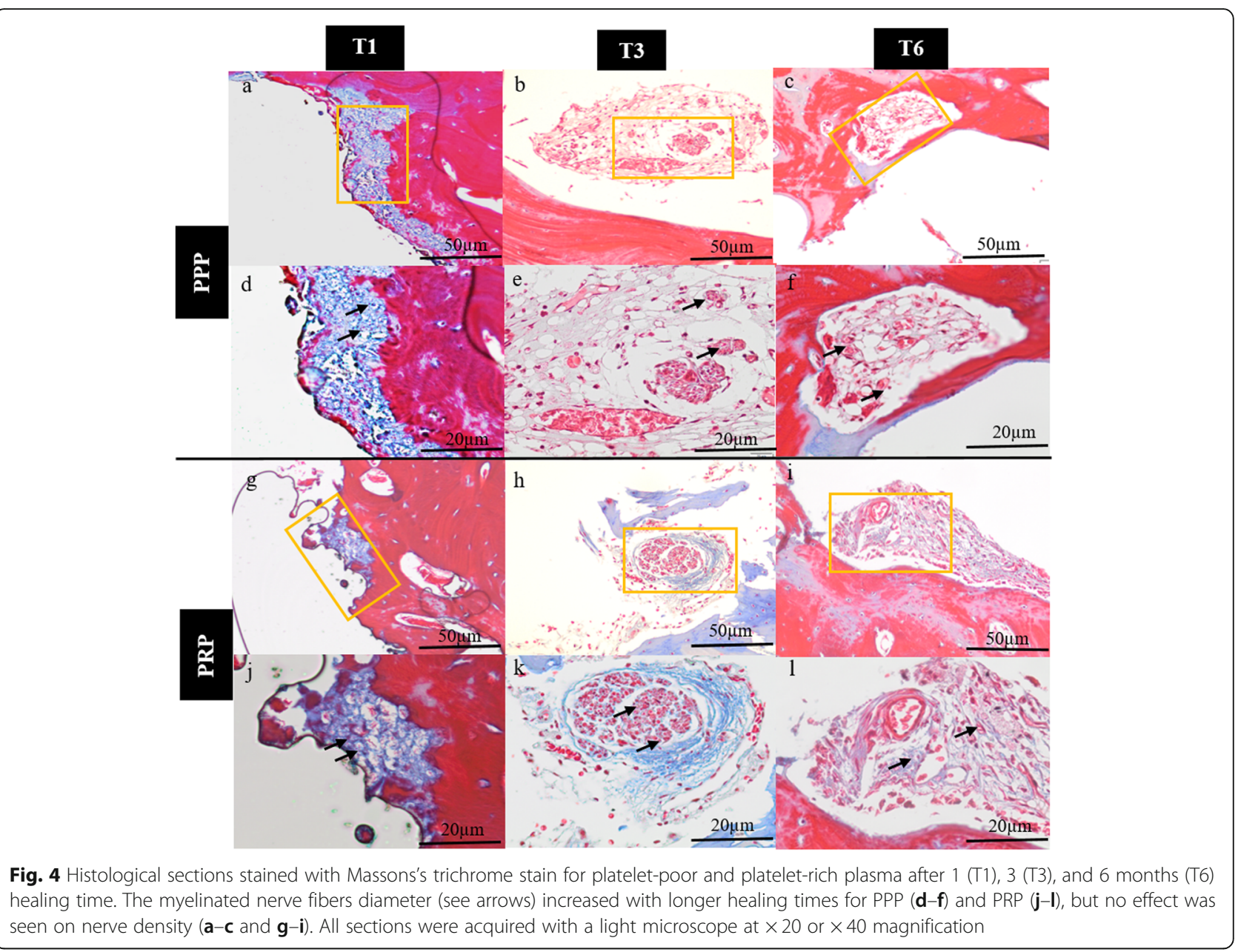

concentration of PRP from the top layer and high concentration of PRP from the bottom layer into the implant bed.

In this study, the density and diameter of myelinated nerve fibers were examined in the region of $500 \mu \mathrm{m}$ away from implant because the mechanoreceptors in this zone are considered to be easily activated by the loading pressure [29]. For minimizing the potential bias between experimental animals, a split-mouth design was applied with identical implant placement and the platelet plasma treatment protocols. The results showed a significant increase in diameter of myelinated nerve fibers after 3 and 6 months healing time. Furthermore, PRP exhibited a significant effect on the diameter of the myelinated nerve fibers as compared to PPP, with bigger diameter fibers observed in the PRP group. Wada et al. [35] reported an increase in the number of neurofilament protein (NFP)-positive nerve fibers after 4 months loading time.

When comparing myelinated nerve density amongst all three groups, a tendency was observed that PPP or PRP might help to improve regeneration of nerve fibers in peri-implant bone, more specifically 6 months after healing. Yet, this observation did not reach significance. This outcome could be explained based on short life of platelets (approximately 5-7 days) [36] and method of platelet plasma preparation and application. Literature reported that the concentration of PRP is dependent on its preparation process which can consecutively result in broad variability of growth factors [37, 38]. Graziani et. al reported that lower concentration of platelet plasma was better for enhancing cellular proliferation [38]. Cho et.al [39]. also found that PRPs' biological effect on nerve fibers was dependent on its frequency of application and concentration which was not considered in our study. For further experiments, it could be advised to optimize the animal model and application protocol for PRP and use a larger subject sample to verify the present results.

Various surgical options have been applied for repairing injured peripheral nerves [40-42]; however, these strategies fail to provide a suitable regenerative micro-environment at a cellular and molecular level. 
a
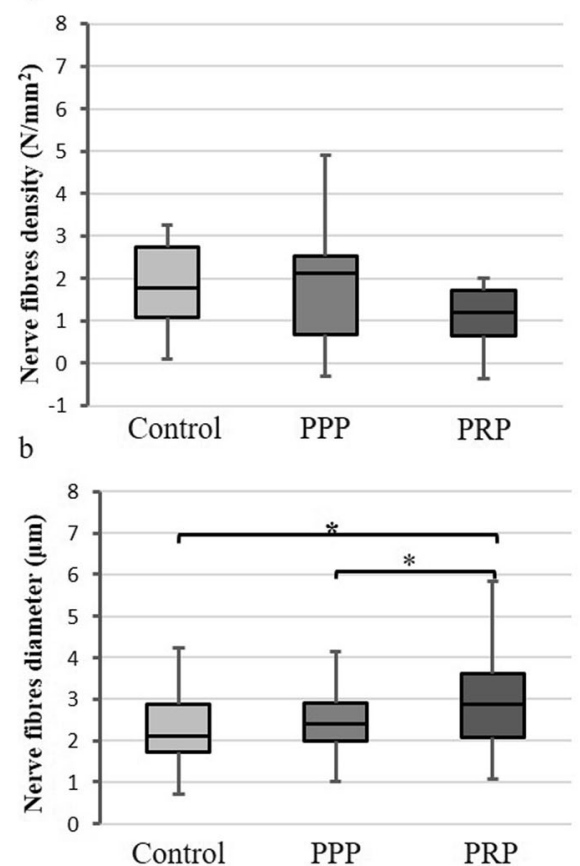
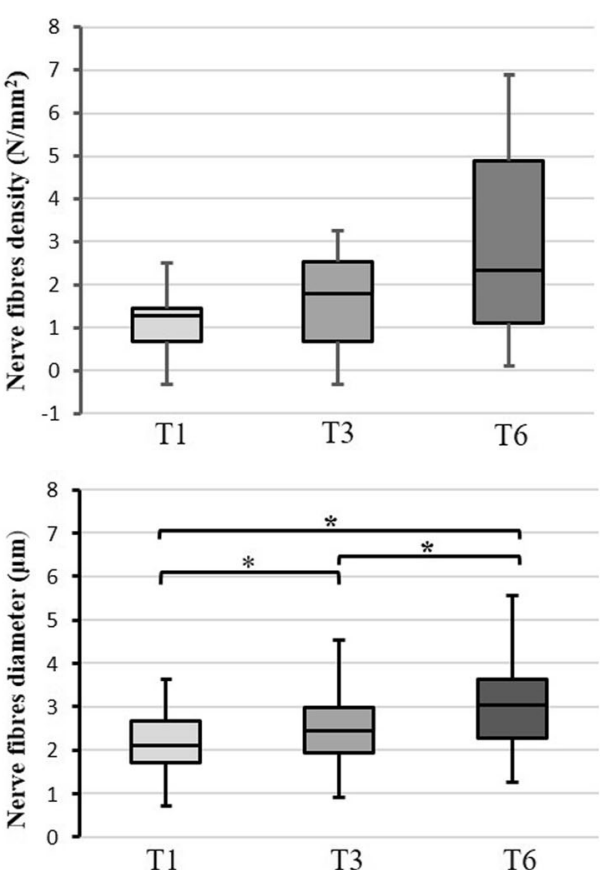

T1
$\mathrm{T} 3$
T6

Fig. 5 Box plots of nerve fiber density (a) and shortest diameter (b) for groups (control, platelet-poor, and platelet-rich plasma) and healing time $(1,3$, and 6 months). The boundary the closest to 0 indicates the 25 th percentile, a black line within the box marks the median, and the farthest from 0 indicates the 75th percentile. Whiskers above and below indicate the 10th and 90th percentile. No difference was observed in the myelinated nerve density, but a significant difference $(p<0.05$ indicated by an asterisk) was found for the shortest nerve diameter between groups and healing time

To overcome this limitation, PRP has been applied as an adjuvant therapeutic strategy for promoting nerve regeneration and repair [43]. Recent evidence suggests a desirable effect of PRP related to regeneration of injured peripheral nerves and it has been successfully applied clinically for sensory and motor fibers repair of neuromuscular units [44]. In the same instance, PRP-coated dental implants have also shown to promote bone regeneration and accelerate soft tissue healing [40]. However, there is lack of evidence demonstrating the effect of PRP using inferior alveolar nerve and lingual nerve models. Based on our findings, we believe that local application of PRP in cases of iatrogenic inferior alveolar and lingual nerve damage during routine implant surgery may provide accelerated healing and regeneration of nerve fibers, thereby improving neurosensory recovery.

Despite the current study limitations, the present report provides for the first time an animal model to evaluate regeneration of injured nerve fibers in the proximity of dental implants. It is considered a step forward in understanding PRPs' influence on implant rehabilitation surgery. Further studies should be performed to develop a standardized protocol for PRP preparation and application in the peri-implant region and assessing its effect on osseoperception.

\section{Conclusions}

The present study showed that the healing time significantly influenced the diameter of the myelinated nerve fibers in the peri-implant bone. PRP exerted a significant effect on the diameter of the myelinated nerve fibers as compared to PPP. Large-scale animal studies and longer follow-up periods are needed to confirm these findings and to verify whether platelet plasma can facilitate nerve regeneration process.

\section{Acknowledgements}

The authors are thankful to the laboratory technicians from the Research Base of West China Hospital, Sichuan University and Translational Cell and Tissue Research of University Hospitals Leuven, KU Leuven for their valuable help during this animal research, and to Xin Li (KU Leuven) for her help with the histological digitalization.

\section{Authors' contributions}

$H Y, C P$, and RJ designed this study. HY did the animal experiment. TV, KVE, $\mathrm{IL}$, and TR helped with the histological staining. DS performed the measurements. JVD did the statistical analysis. SD wrote the first draft of the manuscript. SS, JVD, KO, and RJ corrected the manuscript. All authors have read and approved the final manuscript.

\section{Funding}

This work was supported by a Sichuan Province Science and Technology Support Program (2016SZ0010). DS received fellowship support from the China Scholarship Council (201708210187). HY is a postdoctoral (11.N3.615N) and JVD is a predoctoral (11.ZU.117N) FWO-research fellow. 


\section{Availability of data and materials}

The datasets used and/or analyzed during the current study are available from the corresponding author on reasonable request.

\section{Ethics approval and consent to participate}

This animal experiment was approved by the Bioethics Committee of Sichuan University (reference number: WCCSIRB-D-2014-010).

\section{Consent for publication}

Not applicable.

\section{Competing interests}

The authors declare that they have no competing interests.

\section{Author details}

'OMFS IMPATH Research Group, Department of Imaging and Pathology, Faculty of Medicine, KU Leuven and Oral and Maxillofacial Surgery, University Hospitals Leuven, Campus Sint-Rafaël, Kapucijnenvoer 33, BE-3000 Leuven, Belgium. ${ }^{2}$ State Key Laboratory of Oral Diseases, West China College of Stomatology, Sichuan University, Chengdu, China. ${ }^{3}$ Department of Dentomaxillofacial Radiology, Faculty of Dentistry, University of Ankara, Ankara, Turkey. ${ }^{4}$ Group of Morphology, Biomedical Research Institute, Hasselt University, Diepenbeek, Belgium. ${ }^{5}$ Translational Cell \& Tissue Research, Department of Imaging \& Pathology, KU Leuven, Leuven, Belgium.

${ }^{6}$ Department of Dental Medicine, Karolinska Institute, Stockholm, Sweden.

\section{Received: 16 May 2019 Accepted: 24 October 2019}

\section{Published online: 04 December 2019}

\section{References}

1. Gallucci GO, Hamilton A, Zhou W, Buser D, Chen S. Implant placement and loading protocols in partially edentulous patients: A systematic review. Clin Oral Implants Res. 2018:29:106-34.

2. Pietrokovski J, Kaffe I, Arensburg B. Retromolar ridge in edentulous patients: clinical considerations.J Prosthodont. 2007;16(6):502-6.

3. Hughes FJ. Chapter 34 - Periodontium and Periodontal Disease. In: Vishwakarma A, Sharpe P, Shi S, Ramalingam M, editors. Stem Cell Biology and Tissue Engineering in Dental Sciences. Boston: Academic Press; 2015. p. 433-44.

4. Wadhwa S, Nanda R, Pilbeam C. Chapter 26-Mechanotransduction of Orthodontic Forces. In: Nanda R, Kapila S, editors. Current Therapy in Orthodontics. Saint Louis: Mosby; 2010. p. 339-52.

5. Lambrichts I, Creemers J, van Steenberghe D. Morphology of neural endings in the human periodontal ligament: an electron microscopic study. J Periodontol Res. 1992;27(3):191-6.

6. Jacobs R, van Steenberghe D. Role of periodontal ligament receptors in the tactile function of teeth: a review. J Periodontol Res. 1994;29(3):153-67.

7. Mühlbradt L, Ulrich R, Möhlmann H, Schmid H. Mechanoperception of natural teeth versus endosseous implants revealed by magnitude estimation. Int J Oral Maxillofac Implants. 1989;4(2):125-30.

8. Jacobs R, van Steenberghe D. Comparative evaluation of the oral tactile function bv means of teeth or implant-supported prostheses. Clin Oral Implants Res. 1991;2(2):75-80.

9. Jacobs $R$, van Steenberghe D. Comparison between implant-supported prostheses and teeth regarding passive threshold level. Int J Oral Maxillofac Implants. 1993;8(5):549-54.

10. Hämmerle $\mathrm{CH}$, Wagner $\mathrm{D}$, Brägger U, Lussi A, Karayiannis A, Joss A, et al. Threshold of tactile sensitivity perceived with dental endosseous implants and natural teeth. Clin Oral Implants Res. 1995:6(2):83-90.

11. van Steenberghe D. From osseointegration to osseoperception. J Dent Res. 2000;79(11):1833-7.

12. Jacobs R, van Steenberghe D. From osseoperception to implant-mediated sensory-motor interactions and related clinical implications. J Oral Rehabil. 2006;33(4):282-92

13. Van Loven K, Jacobs R, Swinnen A, Van Huffel S, Van Hees J, Van Steenberghe D. Sensations and trigeminal somatosensory-evoked potentials elicited by electrical stimulation of endosseous oral implants in humans. Arch Oral Biol. 2000:45(12):1083-90

14. Wang Y-HKT, Ando H, Nakanishi E, Yoshizawa $H$, Zhang M, Fukuyama $H$, Wada S, Uchida Y. Nerve regeneration after implantation in peri-implant area. A histological study on different implant materials in dogs.
Osseoperception. In: Jacobs R. (editor) Osseoperception. Leuven. 1998. p.311.

15. Lambrichts I. Histological and ultrastructural aspects of bone innervation. In: Jacobs R. (editor) Osseoperception. Leuven. 1998. p.13-20

16. Corpas LD, Lambrichts I, Quirynen M, Collaert B, Politis C, Vrielinck L, et al. Peri-implant bone innervation: Histological findings in humans. Eur J Oral Implantol. 2014;7(3):283-92.

17. Choi B-H. Periodontal ligament formation around titanium implants using cultured periodontal ligament cells: a pilot study. Int J of Oral Maxillofac Implants. 2000;15(2)

18. Yuan Q, Gong P, Tan Z. Schwann cell graft: a method to promote sensory responses of osseointegrated implants. Med Hypotheses. 2007:69(4):800-3.

19. Ma L, Xiang L, Yao Y, Yuan Q, Li L, Gong P. CGRP-alpha application: a potential treatment to improve osseoperception of endosseous dental implants. Med Hypotheses. 2013;81(2):297-9.

20. Huang Y, Jacobs R, Van Dessel J, Bornstein MM, Lambrichts I, Politis C. A systematic review on the innervation of peri-implant tissues with special emphasis on the influence of implant placement and loading protocols. Clin Oral Implants Res. 2015;26(7):737-46.

21. Martínez CE, González SA, Palma V, Smith PC. Platelet-poor and platelet-rich plasma stimulate bone lineage differentiation in periodontal ligament stem cells. J Periodontol. 2016;87(2):e18-26.

22. Shahidi M, Vatanmakanian M, Arami MK, Shirazi FS, Esmaeili N, Hydarporian $\mathrm{S}$, et al. A comparative study between platelet-rich plasma and platelet-poor plasma effects on angiogenesis. Med Mol Morphol. 2018;51(1):21-31.

23. Zheng C, Zhu Q, Liu X, Huang X, He C, Jiang L, et al. Improved peripheral nerve regeneration using acellular nerve allografts loaded with platelet-rich plasma. Tissue Eng. Part A. 2014;20(23-24):3228-40.

24. Dhurat $R$, Sukesh M. Principles and methods of preparation of platelet-rich plasma: a review and author's perspective. J Cutan Aesthet Surg. 2014;7(4): 189.

25. Huang Y, van Dessel J, Martens W, Lambrichts I, Zhong WJ, Ma GW, et al. Sensory innervation around immediately vs. delayed loaded implants: a pilot study. Int J Oral Sci. 2015;7(1):49-55.

26. Faul F, Erdfelder E, Lang A-G, Buchner A. G* Power 3: A flexible statistical power analysis program for the social, behavioral, and biomedical sciences. Behav Res Methods. 2007;39(2):175-91.

27. Lee JW, Kwon OH, Kim TK, Cho YK, Choi KY, Chung HY, et al. Platelet-rich plasma: quantitative assessment of growth factor levels and comparative analysis of activated and inactivated groups. Arch Plast Surg. 2013:40(5):530.

28. Huang Y, Corpas LS, Martens W, Jacobs R, Lambrichts I. Histomorphological study of myelinated nerve fibres in the periodontal ligament of human canine. Acta Odontol Scand. 2011;69(5):279-86.

29. Weiner S, Klein M, Doyle JL, Brunner M. Identification of axons in the periimplant region by immunohistochemistry. Int J of Oral Maxillofac Implants. 1995; 10(6):689-95

30. Linden $R$, Scott B. The effect of tooth extraction on periodontal ligament mechanoreceptors represented in the mesencephalic nucleus of the cat. Arch Oral Biol. 1989:34(12):937-41.

31. Anjayani S, Wirohadidjojo YW, Adam AM, Suwandi D, Seweng A, Amiruddin MD. Sensory improvement of leprosy peripheral neuropathy in patients treated with perineural injection of platelet-rich plasma. Int J Dermatol. 2014:53(1):109-13.

32. Khojasteh A, Hosseinpour S, Nazeman P, Dehghan M. The effect of a platelet-rich fibrin conduit on neurosensory recovery following inferior alveolar nerve lateralization: a preliminary clinical study. Int J Oral Maxillofac Surg. 2016;45(10):1303-8.

33. Whitman DH, Berry RL, Green DM. Platelet gel: an autologous alternative to fibrin glue with applications in oral and maxillofacial surgery. J of Oral Maxillofac Surg. 1997;55(11):1294-9.

34. Dolder JVD, Mooren R, Vloon AP, Stoelinga PJ, Jansen JA. Platelet-rich plasma: quantification of growth factor levels and the effect on growth and differentiation of rat bone marrow cells. Tissue Eng. 2006;12(11):3067-73.

35. Wada S, Kojo T, Wang YH, Ando H, Nakanishi E, Zhang M, et al. Effect of loading on the development of nerve fibers around oral implants in the dog mandible. Clin Oral Implants Res. 2001;12(3):219-24.

36. Yamazaki T, Sabit H, Oya T, Ishii Y, Hamashima T, Tokunaga A, et al. Activation of MAP kinases, Akt and PDGF receptors in injured peripheral nerves. J Peripher Nerv Syst. 2009;14(3):165-76.

37. Anitua E, Sánchez M, Orive G, Andia I. Delivering growth factors for therapeutics. Trends Pharmacol Sci. 2008;29(1):37-41. 
38. Graziani F, Ivanovski S, Cei S, Ducci F, Tonetti M, Gabriele M. The in vitro effect of different PRP concentrations on osteoblasts and fibroblasts. Clin Oral Implants Res. 2006;17(2):212-9.

39. Cho HH, Jang S, Lee SC, Jeong HS, Park JS, Han JY, et al. Effect of neuralinduced mesenchymal stem cells and platelet-rich plasma on facial nerve regeneration in an acute nerve injury model. The Laryngoscope. 2010; 120(5):907-13.

40. Albanese A, Licata ME, Polizzi B, Campisi G. Platelet-rich plasma (PRP) in dental and oral surgery: from the wound healing to bone regeneration. Immun Ageing. 2013;10(1):23.

41. Tabrizi R, Pourdanesh F, Jafari S, Behnia P. Can platelet-rich fibrin accelerate neurosensory recovery following sagittal split osteotomy? A double-blind, split-mouth, randomized clinical trial. Int J Oral Surg. 2018;47(8):1011-4.

42. Sánchez M, Anitua E, Delgado D, Sanchez P, Prado R, Orive G, et al. Plateletrich plasma, a source of autologous growth factors and biomimetic scaffold for peripheral nerve regeneration. Expert Opin Biol Ther. 2017;17(2):197-212.

43. Sánchez M, Garate A, Bilbao AM, Oraa J, Yangüela F, Sánchez P, et al. Platelet-Rich Plasma for Injured Peripheral Nerves: Biological Repair Process and Clinical Application Guidelines. IntechOpen: Neuropathies; 2018.

44. Bastami F, Vares P, Khojasteh A. Healing Effects of Platelet-Rich Plasma on Peripheral Nerve Injuries. J Craniofac Surg. 2017;28(1):e49-57.

\section{Publisher's Note}

Springer Nature remains neutral with regard to jurisdictional claims in published maps and institutional affiliations.

\section{Submit your manuscript to a SpringerOpen ${ }^{\circ}$ journal and benefit from:}

- Convenient online submission

- Rigorous peer review

- Open access: articles freely available online

- High visibility within the field

- Retaining the copyright to your article

Submit your next manuscript at $\boldsymbol{\nabla}$ springeropen.com 